\title{
In Vitro Testing of Lumbar Disc Arthroplasty Devices
}

\author{
Denis J. DiAngelo a,b, ${ }^{\text {, }}$, Kevin T. Foley ${ }^{\mathrm{a}, \mathrm{b}}$, Brian P. Morrow ${ }^{\mathrm{a}}$, Peter Wong ${ }^{\mathrm{a}}$, Kelly Kiehm ${ }^{\mathrm{b}}$, Anthony \\ $\mathrm{Sin}^{\mathrm{b}}$, Rudolf Bertagnolic, Celeste Abjornson ${ }^{\$}$ and Brian P. Kelly ${ }^{\mathrm{a}}$ \\ ${ }^{a}$ Department of Orthopedic Surgery and Biomedical Engineering, University of Tennessee Health Science Center, \\ Memphis, TN, USA \\ ${ }^{b}$ Department of Neurosurgery, University of Tennessee Health Science Center, Memphis, TN, USA \\ ${ }^{c}$ Spine Center, St. Elizabeth Klinikum, Straubing, Germany \\ ${ }^{\$}$ Synthes Spine, West Chester, PA Research support from Synthes Spine, West Chester, PA and use of the surgical \\ facilities at the Medical Education and Research Institute, Memphis, TN, USA
}

\begin{abstract}
Background Context: Interest in lumbar disc arthroplasty as an alternative to fusion surgery continues to grow. The goal of disc arthroplasty is to replace the diseased disc while preserving and/or restoring motion at the operated spinal level. Different paradigms exist in the design of total disc arthroplasty devices. Purpose: The purpose of this study was to compare the in vitro biomechanics of a more constrained ball-and-socket design (Prodisc-L, Synthes Spine and Maverick, Medtronic) and a less constrained mobile-bearing design (Charité, DePuy). The biomechanical performance of the disc prostheses was compared to harvested and fused spine conditions. The fused model was simulated using single-level posterior pedicle screw fixation instrumentation. Study Design/Setting: In vitro test to compare the biomechanical properties of three different lumbar disc replacement devices in a human cadaveric model. Methods: Twenty human cadaveric lumbar spines (L1-sacrum) were tested in flexion, extension, lateral bending, and axial rotation under displacement control to a target bending moment of $8 \mathrm{Nm}$. The spine conditions tested were: harvested spine ( $\mathrm{n}=19$ ); L5-S lumbar disc replacement using Prodisc-L $(\mathrm{n}=13)$; Maverick $(\mathrm{n}=7)$; Charite $(\mathrm{n}=6)$; and L5-S pedicle screw fixation (PSF) $(n=19)$. The first 12 spines were split into 2 groups: 6 were instrumented with the Charite and 6 with the ProDisc-L. The next 7 spines tested were split into 2 groups: 4 instrumented with ProDisc-L and 3 with the Maverick. After completing all tests on the second group of 7, the Maverick and ProDisc-L discs were swapped between spines and retested. The Click'X pedicle screw system (Synthes Spine) was used to simulate the fusion model in all spines tested. For axial rotation tests, a $100 \mathrm{~N}$ compressive load was applied. Measurements included vertebral motions, total spine rotation, and applied loads. The percent contribution of rotation at the instrumented (L5-S) level relative to total rotation (L1-S), as well as at the remaining adjacent levels relative to total rotation, was determined a common load limit $(8 \mathrm{Nm})$ and compared using a one-way ANOVA and SNK test $(\mathrm{P}<0.05)$. Results: A significant reduction in motion occurred at the operated level of PSF condition compared to the three disc arthroplasty conditions for all loading modes. No differences occurred between the 3 disc conditions for all modes tested, except at the instrumented level of the ProDiscL (93\% of H) and Maverick (128\% of $\mathrm{H})$ spine conditions during combined flexion+extension. The reduced motion at the operative level of the PSF condition was transferred to the adjacent levels and caused a significant increase in motion during combined flexion+extension at all adjacent levels for the 3 disc arthroplasty conditions, during combined right+left lateral bending at L1-L2 for all disc conditions and at L3-L4 for the Charite, and during combined right+left axial rotation at L3-L4 for all three disc conditions. Conclusions: Issues pertaining to adjacent segment disease (ASD) with pedicle screw fixation were supported by increased motion contributions at multiple sub-adjacent segments. However, disc arthroplasty eliminated any significant increase and may prevent ASD. Compared to pedicle screw fixation, the three differently designed disc prostheses (Prodisc-L, Maverick, and Charité) remained stable and provided improved lumbar mobility. The only notable difference between the disc designs was the increased combined flexion+extension motion at the operative level of the Maverick disc compared to the ProDisc-L device.
\end{abstract}

Keywords: Lumbar spine, biomechanical testing, spinal instrumentation, lumbar disc, arthroplasty, biomechanics.

\section{INTRODUCTION}

Back pain is one of the most common reasons to seek care and affects approximately one fourth of the adult

*Address correspondence to this author at the Department of Orthopedic Surgery and Biomedical Engineering, The University of Tennessee Health Science Center, 956 Court Ave., Suite E226, Memphis, TN 38163, USA;

Tel: 901-448-7744; Fax: 901-448-7387; E-mail: ddiangelo@uthsc.edu population in the United States [1]. When conservative treatments for this disease fail, surgery may be indicated. For lumbar spine structural pain, the gold standard surgical treatment has been vertebral body fusion. Reported drawbacks and complications associated with spinal fusion surgery have included the need for external orthosis, the development of pseudoarthrosis, which may be associated with continued symptoms of back pain, the degeneration of 
Table 1. Design features of lumbar total disc replacement devices.

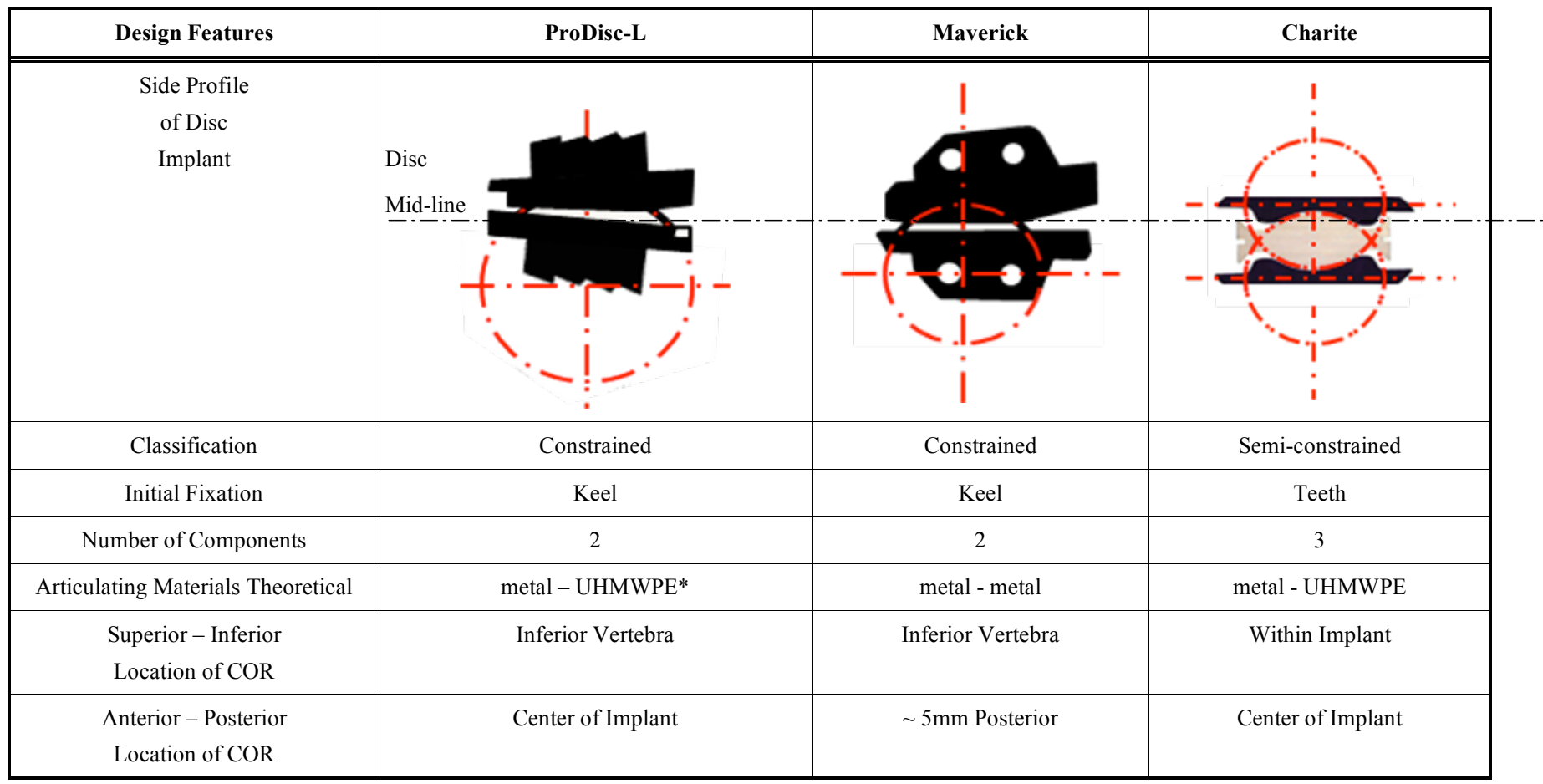

*UHMWPE: ultra high molecular weight polyethylene

levels adjacent to the fused region, or not work to help resolve the patient's symptoms [2-7]. Use of motion preservation devices, including total disc arthroplasty, has recently become a potential alternative to fusion that aims to overcome some of these limitations by replacement of the diseased disc, restoration of disc space height, and preservation of motion at the operated spinal level [8]. Disc arthroplasty offers the potential to not only treat the underlying disc mediated pain, but better control the advancement of degenerative disease at the adjacent segments.

Different constructs exist in the design of total disc arthroplasty (TDR) devices which vary by the type of motion constraint imposed by the device. One design allows the device to have rotation, similar to a ball and socket joint. The ProDisc-L (DePuy Synthes Spine, West Chester, PA) and the Maverick (Medtronic, Memphis, TN) utilize this feature, but have design differences that may contribute to varied kinematic responses. Another less constrained TDR, the Charité disc implant (Depuy Spine, Raynham, MA), involves a mobile polyethylene core that can translate between components in addition to unconstrained rotation. The core translations make the center of rotation (COR) mobile.

It remains of clinical interest to better understand the effects of these different TDR designs on the biomechanics, replacement level specificity, adjacent segment effects and comparison of function to a healthy lumbar disc and any improvements and/or differences when compared with traditional fusion surgery. The purpose of this study was to compare the in vitro biomechanics of a more constrained ball-and-socket design (Prodisc-L and Maverick) and a less constrained mobile-bearing design (Charité) in a human multi-level cadaveric lumbar spine model. The biomechanical performance of the disc prostheses was compared to harvested and fixated spine conditions. The fixated model was simulated using single-level posterior pedicle screw fixation instrumentation.

\section{MATERIALS AND METHODS}

\section{Spinal Instrumentation}

Three different disc prostheses were studied: the ProDisc-L (DePuy Synthes Spine, West Chester, PA), Maverick (Medtronic, Memphis, TN), and Charité disc implant (DePuy Synthes Spine, Raynham, MA). A list of design features describing these three TDRs is given in Table 1. The ProDisc-L has an articulating surface with a $14.5 \mathrm{~mm}$ (medium size) or $16.5 \mathrm{~mm}$ (large size) radius of curvature, whereas the Maverick has a $10 \mathrm{~mm}$ (nominal) radius of curvature. The COR for both of these constrained disc designs are located in the subjacent body. The COR of the Charite disc is located at the center of the disc along the anterior-posterior midline similar to the ProDisc-L. The COR location of the Maverick disc is approximately $5 \mathrm{~mm}$ posterior to that of the ProDisc-L. Variations in the COR placements are illustrated in Table $\mathbf{1 .}$

\section{Specimen Preparation}

Twenty fresh frozen human cadaveric lumbar spines with mean age of $56.7 \pm 14.9$ years were procured. All spines were screened with anteroposterior and lateral radiographs to exclude any specimens with gross osteopenia or anatomic abnormality. Bone density measurements were not done. 


\section{Flexion + Extension Motion Profiles for Levels L1-S}

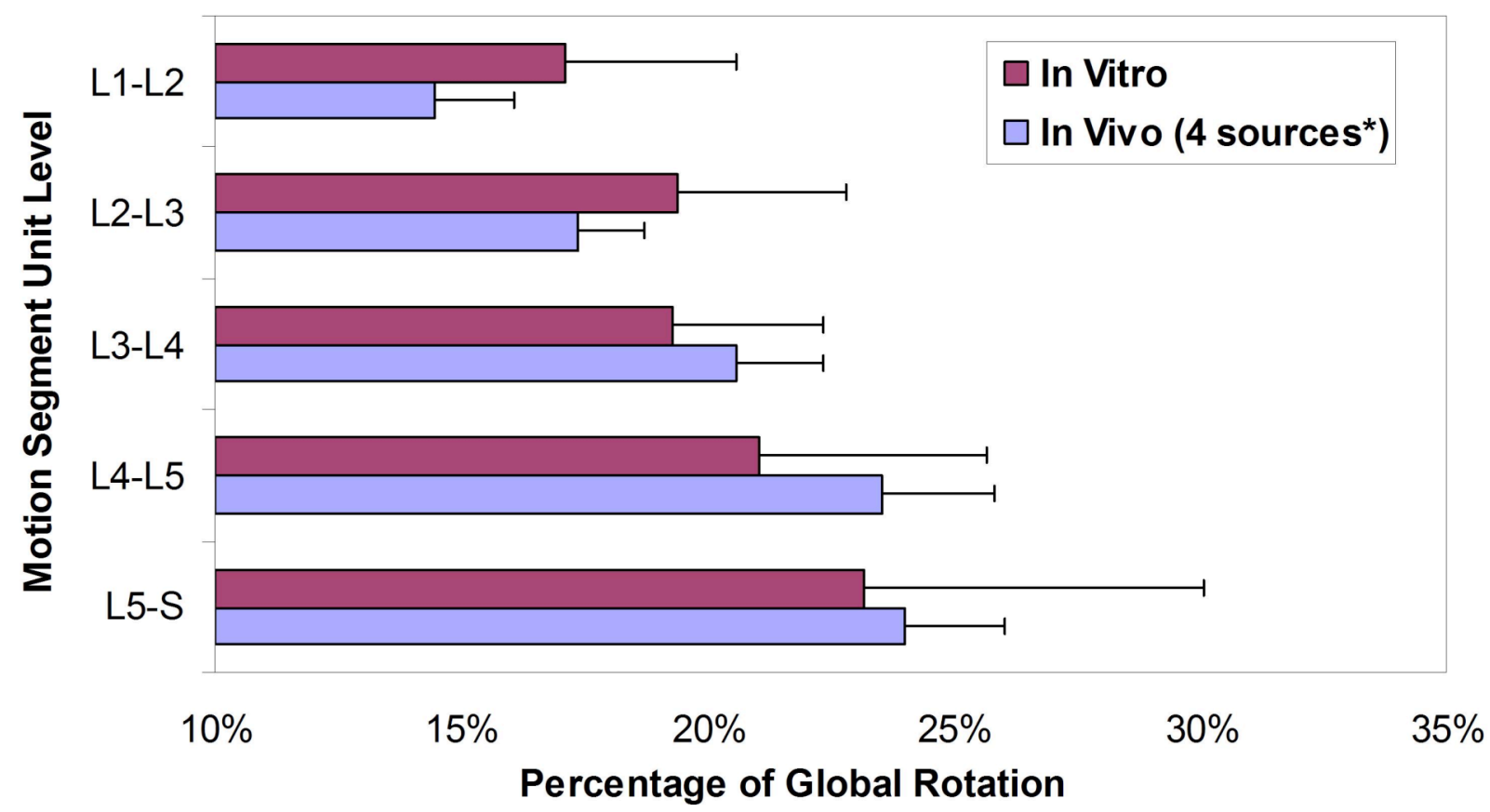

Fig. (1). Bar graph showing combined flexion/extension MSU rotations for in vitro testing method compared with published in vivo* data [13-16].

However, any specimen that was unable to provide adequate end plate purchase to prevent subsidence, as determined by the spine surgeons, was not used. One specimen was discarded due to poor tissue quality for implant fixation reducing the total sample size to nineteen.

For each specimen surrounding paravertebral soft tissues were dissected while preserving spinal ligaments, discs, and bone. The posterior elements were not removed for testing. Specimens were potted in a neutral, upright orientation with low-melting-point, bismuth alloy (Small Parts, Miami Lakes, FL) applied to the L1 vertebral body and sacrum. Threaded rods were placed into the lateral aspects of the vertebral bodies to secure light emitting diode (LED) targets used with an optical motion tracking system. Target attachment did not interfere with the placement of lumbar disc prosthesis or pedicle screw instrumentation.

\section{Nondestructive Testing Protocol}

Although various in vitro testing methods have been employed to study the stability of lumbar spinal instrumentation, the pure moment loading method is the most common [9]. Pure moment methods are suitable for ranking different fixation systems. However, they are less appropriate for studying motion preservation or non-fusion instrumentation systems, as they do not replicate physiologic loading conditions nor do they induce physiologic motion responses at segments adjacent to an instrumented level. The same holds true for hybrid testing methods [10] that force an erroneous amount of motion compensation to occur at noninstrumented segments by forcing all instrumented spine conditions, including fixated conditions, to obtain the same global motion response of the intact spine condition.
As the lumbar spine flexes or extends in vivo from a neutral upright orientation, the weight of the upper body acts eccentric to the lumbar spine. When this body load is transferred to the top of the lumbar spine, a compressive load and bending moment occur. An eccentric load testing protocol [11, 12] was developed and used that applied a compressive load eccentric to the long axis of the spine which induced a bending moment distribution across the spinal construct that increased in the caudal direction. This protocol has been used to study other lumbar spinal instrumentation $[11,12]$. Validation of the eccentric load testing protocol was provided by the close congruence of in vitro flexion/extension motion response shown in Fig. (1) to that of published in vivo data [13-16].

The experimental set up for flexion and extension is shown in Fig. (2). A single tension/compression load cell (Transducer Technologies, Temecula, CA) was positioned in-line with the actuator shaft. The other end of the load cell connected to an upper mounting fixture assembly that included a linear bearing and pinned assembly connected to slotted shaft that attached to the spine. The offset between the center of the upper potted spinal body and the actuator was $200 \mathrm{~mm}$. The linear bearing provided a nearly frictionless connection to the splined shaft to reduce applied shear forces during the movement of the actuator. With the load axis of the actuator eccentric to the spine, a compressive force $(25 \mathrm{~N} \mathrm{L1}$ pot + applied load) and flexion/extension bending moment were applied to the spine. The spine was rotated 90 degrees in the mounting fixtures to apply a lateral bending moment. A rotational displacement transducer (Data Instruments, Acton, MA) was attached to the upper pinned assembly and measured the global rotation of spine. The displacement transducer recorded changes in the moment 


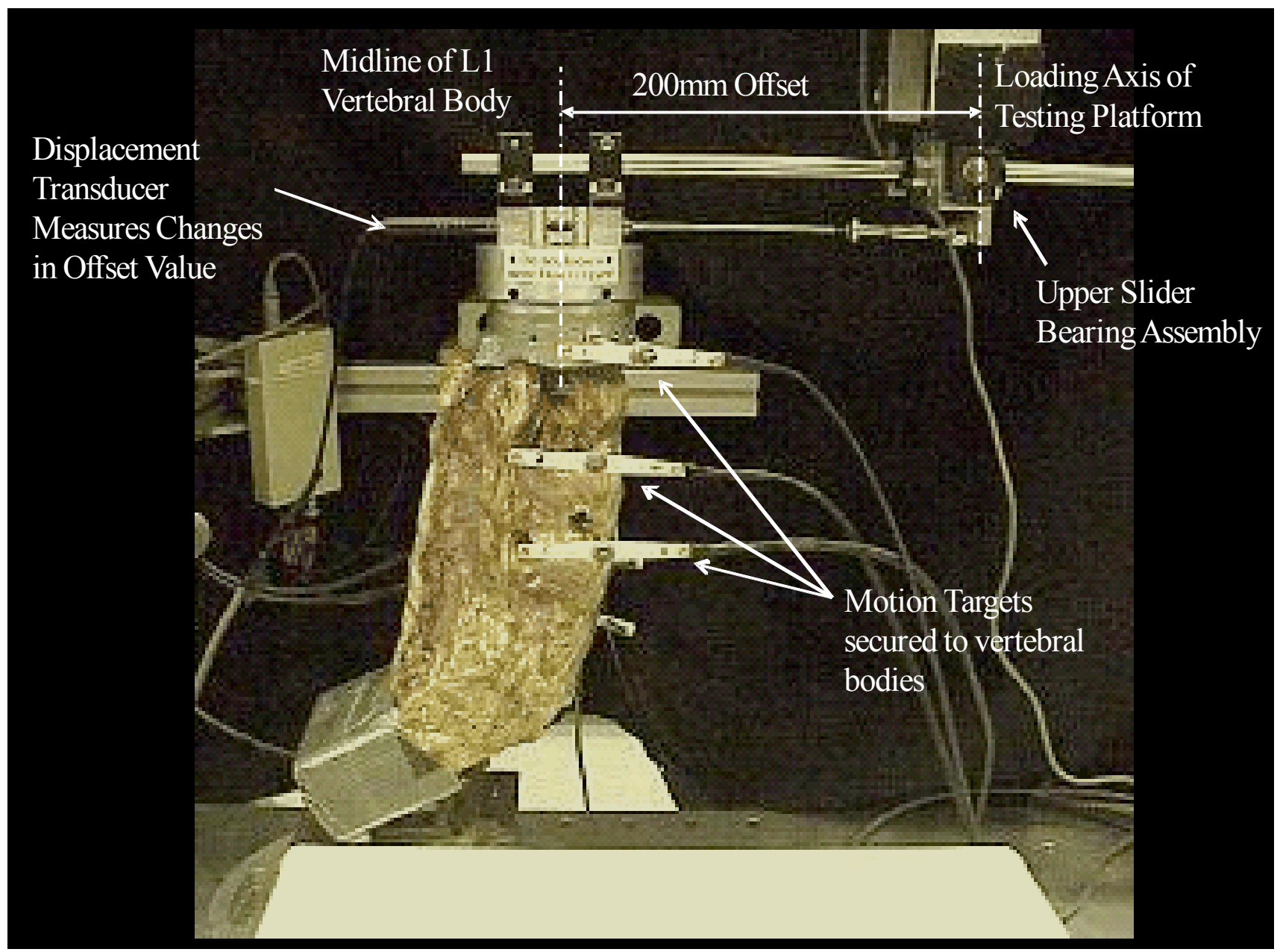

Fig. (2). Experimental Setup for Flexion/Extension Eccentric Load Testing Protocol.

arm length between the upper pot and load axis of the actuator during flexion/extension or lateral bending tests.

The spines were first tested in the Harvested condition in flexion, extension, lateral bending, and axial rotation. For flexion, extension and lateral bending tests, the spine was positioned at a $200 \mathrm{~mm}$ offset from the actuator load axis. Since axial rotation is strongly coupled with lateral bending, the spines were unconstrained in axial rotation during lateral bending tests and unconstrained in lateral bending during axial rotation tests [17-19].

For axial rotational tests, the upper slider bearing assembly was replaced with a vertical linear bearing assembly that constrained the top of the spine from rotating but permitted free upward or downward translation. A turn table mounted on an $x-y$ table was added to the base of the spinal construct. Upward movement of the actuator pulled a cable system that in turn rotated the turntable and applied an axial torque to the spine. A torque load cell inline in line with the vertical linear bearing assembly measured the torque transferred through the spinal construct. A compressive preload of $100 \mathrm{~N}$ was continuously applied to the spine by placing $100 \mathrm{~N}$ stationary weights on top of the L1 pot. This amount falls between the no load condition used with the pure moment test methods and a $400 \mathrm{~N}$ load used with the follower load test protocol. A counterbalancing load of $45 \mathrm{~N}$ was applied to the turntable to return the specimen to the neutral position during the unloading phase. Right and left axial rotations were produced to simplify changing position of the cables that turned the rotary table.

Tests were performed under displacement control with a programmed triangular shaped displacement-time waveform of $6.4 \mathrm{~mm} / \mathrm{sec}$, corresponding to approximately $2.0 \mathrm{deg} / \mathrm{sec}$ overall spine motion. Specimens were nondestructively tested in flexion/extension and lateral bending to a target bending moment of $8 \mathrm{Nm}$. This target moment of $8 \mathrm{Nm}$ falls within the typical load condition used by other spine researchers $[10,11,20-23,24-30]$. Spines were preconditioned with five cycles before testing with each test trial comprised of three loading cycles. To avoid dehydration spines were moistened throughout the study with $0.9 \%$ saline solution.

\section{Spinal Test Conditions}

Following completion of the harvested tests, a conventional anterior discectomy and end plates preparation were performed by a spine surgeon experienced with total disc replacements to prepare for disc implantation after which the spines were tested with the disc implant in place. The discectomy procedure included removal of the anterior longitudinal ligament, anterior annulus, and nucleus pulosus, and extended posteriorly to the posterior longitudinal ligament. All procedures were performed at the Medical 


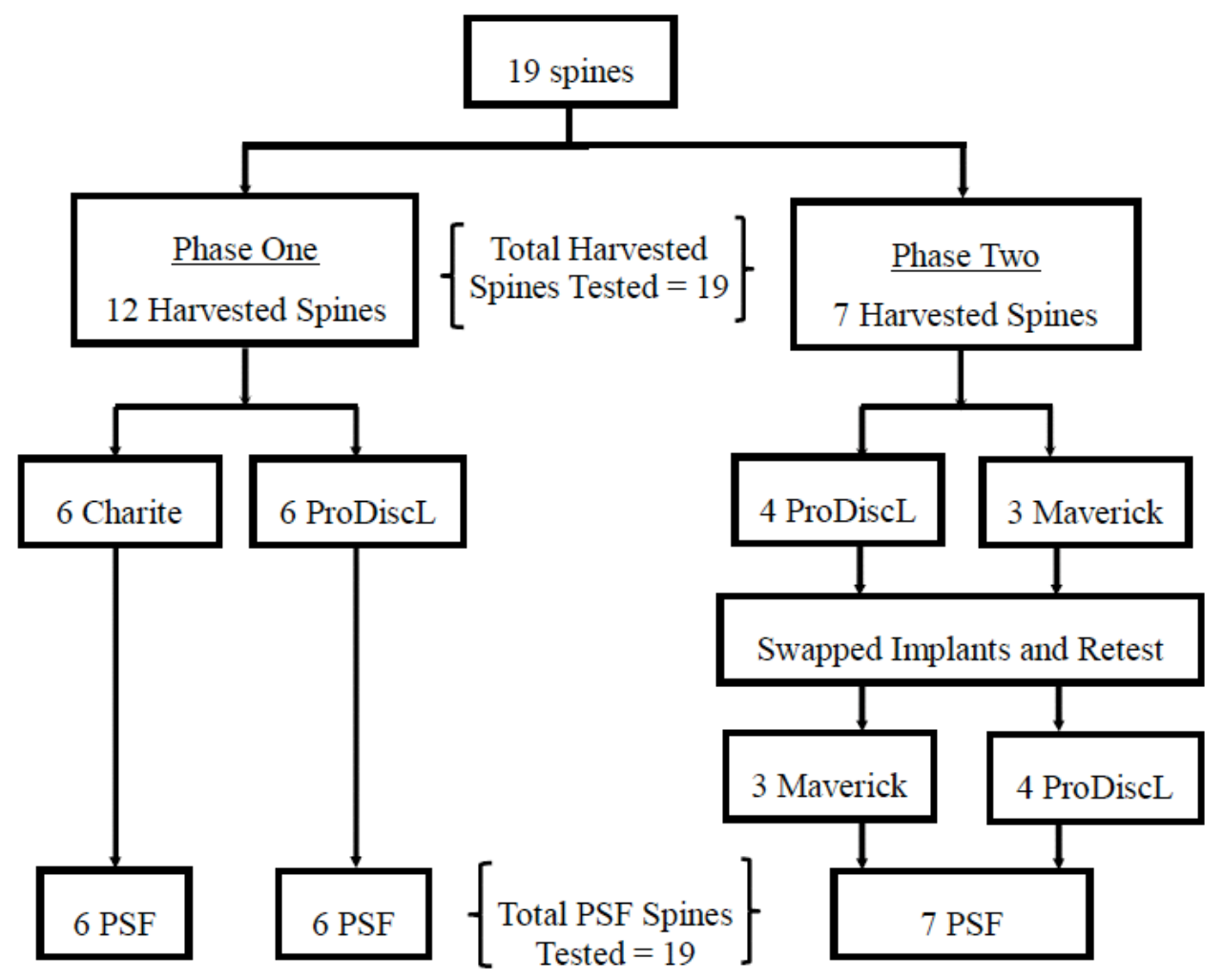

Fig. (3). Flowchart of Spine Test Conditions.

Education Research Institute, (Memphis, TN) as per manufacturer's surgical guidelines.

A total of twenty specimens were procured and five different spine conditions were evaluated. They included the Harvested spine, L5-S1 lumbar disc replacement using ProDisc-L, Maverick, Charité, and L5-S1 pedicle screw fixation (PSF). This study was done in two phases as illustrated in Fig. (3). The first phase of the study compared the ProDisc- $\mathrm{L}$ and Charite discs to the intact and fixated models. In phase One, 12 spines were randomly split into 2 groups: 6 spines were instrumented with the Charité and 6 spines with the ProDisc-L. The second phase of the study compared the ProDisc-L and Maverick discs to the intact and fixated conditions. Eight spines were used in Phase two with four spines allocated per implant type. However, during the surgical placement of one of the maverick discs, one specimen was rejected due to poor tissue quality. This reduced the total specimen count for phase two to 7 specimen.

Unlike in the first phase where only one disc implant was tested per specimen, both discs were tested in each specimen during phase two. That is after the initial implanted spines were tested, all implants were removed. The ProDisc- $\mathrm{L}$ implants were then placed by the spine surgeon as per industry specifications into those specimens that previously had Maverick discs. In a similar way the maverick discs were implanted into the spines that previously been used for the ProDisc-L implants. After all of the re-instrumented spines were tested, the total number of specimens per implant was 7. As such the number of specimens per implant is not equal. However, this did not prevent a valid statistical comparison of the data. The final spine condition to be tested was the instrumented PSF condition.

The 7 remaining harvested spines were split into 2 groups: 4 instrumented with the ProDisc-L and 3 with the Maverick. After completing tests on the second group of 7 , the Maverick and ProDisc-L discs were swapped between spines and retested. The Click'X pedicle screw system (DePuy Synthes Spine) was used to simulate the fixated model in all spines tested with the disc replacement functioning as an inter-body graft (Fig. 4). The disc implants remained in place and the pedicle screw spinal instrumentation was inserted as per manufacturer's specifications under fluoroscopic image guidance to ensure proper sizing and placement. In the end the fixated condition was representative of a typical salvage operation involving pedicle screw and rod instrumentation without disc implant removal. A similar spine condition was tested by Cunningham et al. [31] and found to be biomechanically equivalent to femoral ring allograft with posterior pedicle screw and rod instrumentation.

\section{Data Processing and Management}

Measurements included vertebral body rotations, total spine rotation, and applied loads. The moment applied to the spine at mid-line of L1 vertebral body $\left(\mathrm{M}_{\mathrm{a}}\right)$ was calculated from the vertical force reported by the in-line load cell $\left(\mathrm{F}_{\mathrm{a}}\right)$, the total rotation of the upper pot reported by the rotational transducer $\left(\theta_{\text {rdt }}\right)$, and the displacement offset $\left(\mathrm{d}_{\mathrm{a}}-\mathrm{d}_{\mathrm{tdt}}\right)$ between the upper pot and load axis: $\mathrm{M}_{\mathrm{a}}=\mathrm{F}_{\mathrm{a}}\left(\mathrm{d}_{\mathrm{a}}-\right.$ $\left.\mathrm{d}_{\mathrm{tdt}}\right) / \cos \left(\theta_{\mathrm{rdt}}\right)$, where $\mathrm{d}_{\mathrm{a}}$ is the initial offset distance between the load axis and the center of the upper pot. For each test trial, the vertebral rotation and applied moment data were 


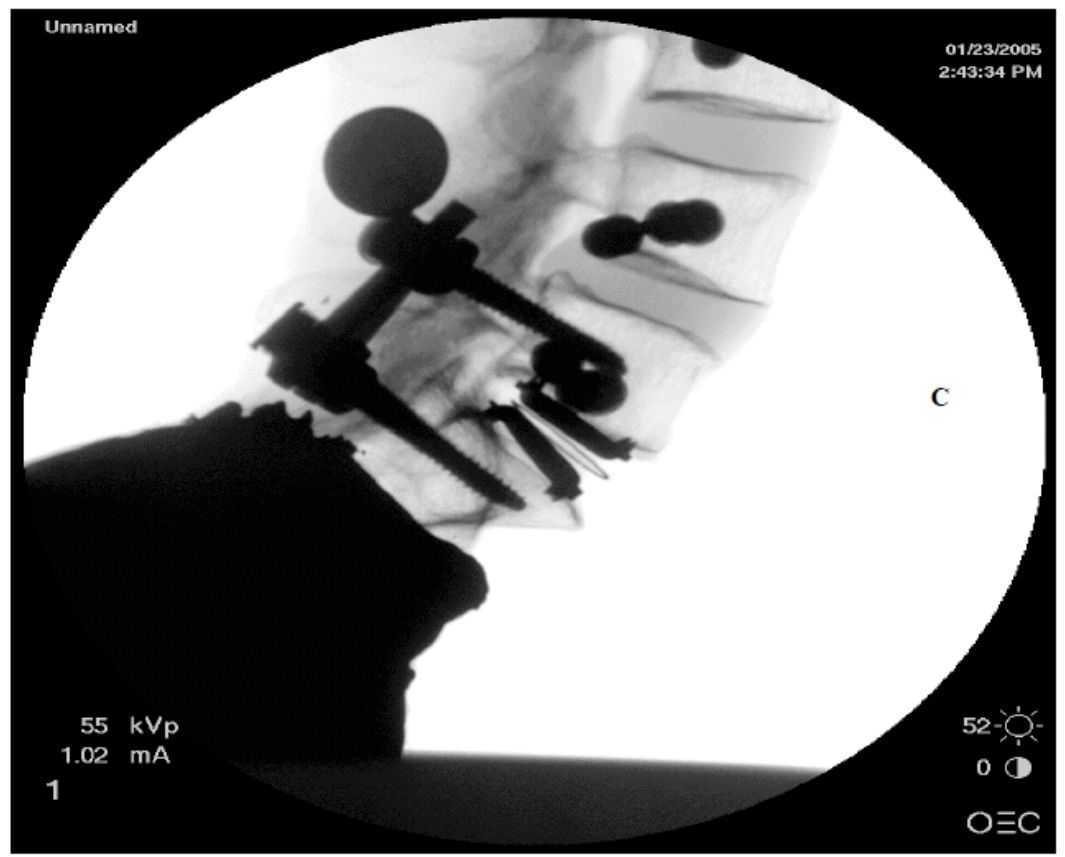

Fig. (4). Post-operative radiograph of the simulated fixated spine condition.

\section{Normalized Flexibility}

(8.0 Nm Global Moment)

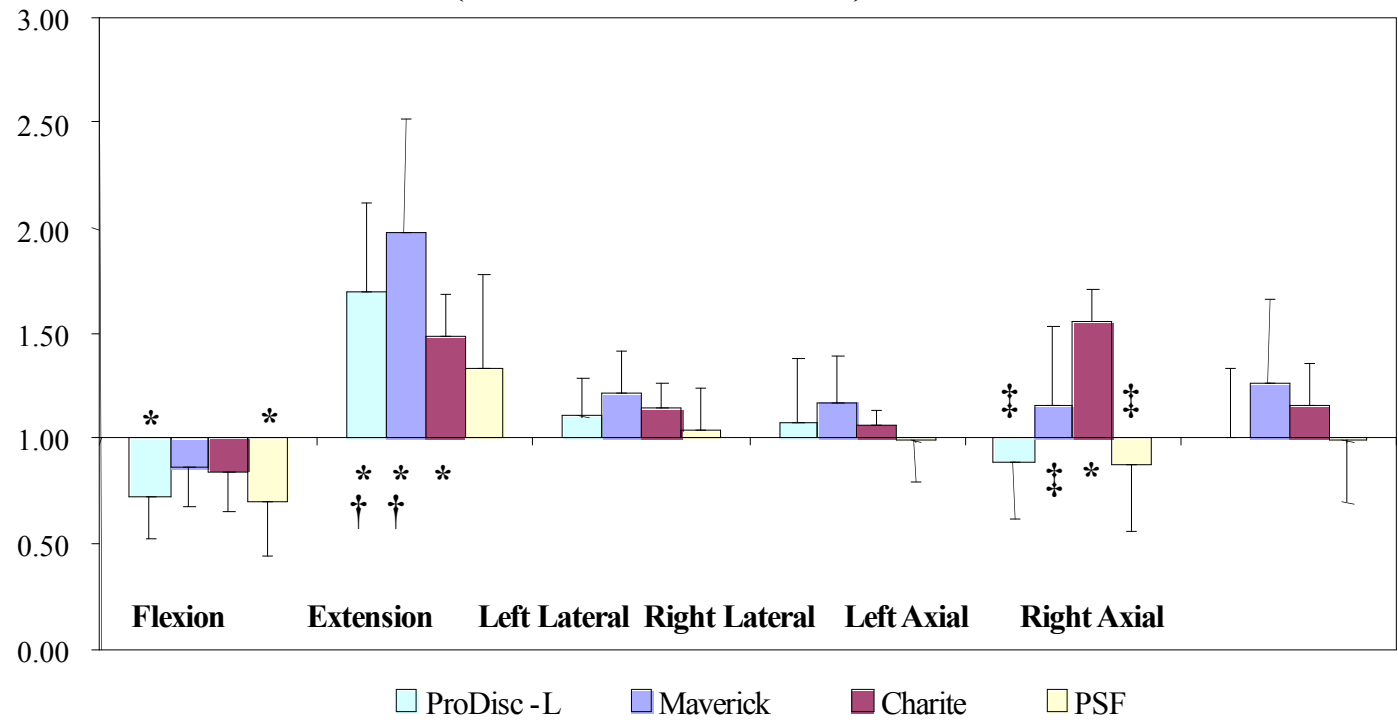

Fig. (5). Normalized flexibility of the altered spine conditions relative to the harvested condition. (* Signifies significant difference between the harvested condition, $\uparrow$ signifies significant difference from the fixated condition, $\$$ signifies significant difference with respect to the Charité implanted condition).

combined to calculate global (L1-S1) spine flexibility which was normalized to the Harvested condition to account for intrinsic differences between specimens. The percent contribution of rotation at the instrumented (L5-S1) level relative to total rotation (L1-S1), as well as at the remaining adjacent levels relative to total rotation, were determined at a common load limit, normalized to corresponding values for the Harvested condition, and statistically compared between instrumented groups. All data analyses were performed at a load limit of $8 \mathrm{Nm}$ bending moment. Statistical tests were conducted using a one-way ANOVA and SNK test $(\mathrm{P}<0.05)$.

\section{RESULTS}

\section{Normalized Flexibility}

Mean normalized global flexibility charts for the four instrumented spine treatments are summarized in Fig. (5). In flexion the fixated spine condition significantly reduced global flexibility by $30 \%$ compared to the Harvested spine condition. All TDR interventions reduced the global flexibility, but only the ProDisc-L significantly reduced the flexibility of the Harvested condition by $28 \%$. In extension 
the Charité, ProDisc-L and Maverick spine conditions significantly increased global flexibility over the Harvested condition by $48 \%, 70 \%$ and $98 \%$, respectively. No other significant differences occurred in all other modes of loading, with the exception of left axial rotation, where the Charité spine condition demonstrated a mean increased flexibility of $55 \%$ over the Harvested case that was significantly different from all other spine conditions.

\section{Relative Motion Segment Unit (MSU) Rotations}

\section{Flexion/Extension}

Mean operated level (L5-S1) and global (L1-S1) spinal rotations are given in Table 2 for all spine conditions. The mean segmental rotations at each spinal level for all spine conditions are provided in Figs. (6 to 8). The percent contribution of each MSU rotation within each spine condition normalized to its contribution in the Harvested case is summarized in Figs. (9 to 11) with statistical differences indicated.

For the Fixated spine condition in flexion-extension, the contribution of operative L5-S1 level to overall spinal rotation was reduced by $72 \%$ compared to its contribution in the Harvested case. The MSU contributions relative to global spinal rotation at levels L1-L2, L2-L3, and L3-L4 for the Fixated condition significantly increased by $33 \%, 28 \%$, and $21 \%$, respectively over the Harvested condition. For the three different disc implants relative motion contributions at all levels were not different from those for the Harvested condition. Significant differences in percent motion contributions between all TDR conditions and the Fixated spine condition occurred at levels L2-L3 and L5-S1, and additionally at L3-L4 for the ProDisc-L and Maverick spine conditions. Between the different types of TDR implants a significant difference occurred between ProDisc-L and Maverick at the L5-S1 level with the Prodisc-L reducing motion contribution by $7 \%$, and the Maverick increasing the contribution by $28 \%$ compared to the Harvested case.

\section{Lateral Bending}

In left-right lateral bending motion contribution at the L5-S1 treated level for the Fixated spine specimen was significantly reduced by $54 \%$ compared to the Harvested case, and significantly different from that of the ProDisc-L, Maverick and Charité implants which reduced the L5-S1 contribution by $14 \%$ and increased it by $17 \%$ and $32 \%$, respectively. No significant differences were found in motion contribution when all levels were added together between TDR and Harvested conditions.

\section{Axial Rotation}

In left-right axial rotation motion contributions for the Fixated condition were significantly reduced by $60 \%$ at the L5-S1 and increased by 53\% at L2-L3 levels compared to the Harvested condition. Motion contributions at the treated L5-S1 level for the ProDisc-L, Maverick and Charité conditions were all significantly different from the Fixated condition and increased relative to the Harvested condition by $9 \%, 51 \%$, and unchanged, respectively.

\section{DISCUSSION}

The ProDisc-L and Maverick implants represent a more constrained ball and socket design of total disc replacement as compared to the mobile core design of the Charité. As previously discussed by Huang et al. [23] more unconstrained designs may have a kinematic advantage via a mobile COR that can better compensate for variations in surgical placement and deviations between the implant and true physiologic location of a moving COR. Additional mobility may also prevent excessive capsuloligamentous and facet loads at extreme flexion or extension. In contrast more constrained ball and socket type designs may have the advantage of shielding the facet joints (posterior spinal elements) from considerable shear forces that occur during daily activities.

Limited biomechanical data are available that characterizes the different TDR design features. In this study, the biomechanical properties of the ProDisc-L, Charite, and Maverick TDR devices were studied using a multi-level lumbar spine model. Hitchon et al. [24] evaluated the Maverick disc implant at L4-L5 under pure moment loading to $6 \mathrm{Nm}$. Their results for the implanted condition showed increased L4-L5 ROM as compared to the Harvested state for all modes of testing (16.3 vs. 10.9 degrees in flexion-extension, 10.8 vs. 8.1 degrees in bi-axial rotation, 18.8 vs. 8.9 degrees in left-right bending). Cunningham et al. [25] reported a significant increase in motion at the instrumented L4-L5 level for the Charité over the harvested condition of $44 \%$ for axial rotation under pure moment loading. Using pure moments with a $400 \mathrm{~N}$ follower load, Goel et al. [26] reported different results of a $26 \%$ increase in flexion and a 98\% increase in extension ROM. O'Leary et al. [27] reported increased segmental range of motion of $47 \%$ in combined flexion-extension over the harvested case, for the Charité at L5-S1.

Using a hybrid protocol with $400 \mathrm{~N}$ follower load Panjabi et al. evaluated both the ProDisc-L and Charité disc implants in independent studies [28, 29]. For the single level Charité at L5-S1 no significant differences in motion at all levels in flexion-extension and bi-axial torsion occurred with a $2.7 \%$ reduction and $24.6 \%$ increase in motion at the operated level respectively. For a single level ProDisc-L at L5-S1 no significant differences in motion at all levels were observed in flexion-extension with a $1.1 \%$ reduction in motion at the operated level as compared to the harvested spine. However, significant increases in L5-S1 segmental motion of 55.5\% and $72.8 \%$ were observed for left-right lateral bending and bi-axial torsion respectively.

Given different in-vitro testing protocols, surgical procedures and variations thereof, it is difficult to speculate on the performance of different implant designs based on these studies. Results from load based investigations may indicate potential for increased ROM with the Maverick and Charité implants though the modes of loading in which increases were observed varied. Additionally, core entrapment with the Charite which locked the mobile core over a portion of the range of motion in 8 of 10 implants was also observed by O'Leary et al. [27] which indicated that total disc replacements may not always function as intended. 
Table 2. MSU rotations of all spine conditions for all modes of testing in degrees. (mean \pm standard deviation).

\begin{tabular}{|c|c|c|c|c|c|c|}
\hline & & \multicolumn{3}{|c|}{ Flexion } & \multirow[b]{2}{*}{ L5-S1 } & \multirow[b]{2}{*}{ L1-S1 Total } \\
\hline & L1-L2 & L2-L3 & L3-L4 & L4-L5 & & \\
\hline Harvested & $-5.0(1.8)$ & $-4.3(1.5)$ & $-5.4(1.9)$ & $-5.7(1.9)$ & $-5.9(2.3)$ & $26.3(5.2)$ \\
\hline Prodisc-L & $-3.8(2.3)$ & $-2.9(1.0)$ & $-3.2(1.1)$ & $-3.7(1.1)$ & $-3.3(1.6)$ & $16.9(4.8)$ \\
\hline Maverick & $-4.7(2.1)$ & $-4.0(1.7)$ & $-5.0(1.8)$ & $-4.5(1.7)$ & $-5.2(2.6)$ & $23.4(7.5)$ \\
\hline Charite & $-4.5(1.5)$ & $-4.2(1.9)$ & $-5.2(1.8)$ & $-5.9(2.7)$ & $-4.9(1.2)$ & $24.8(7.9)$ \\
\hline Fusion & $-4.4(2.0)$ & $-3.7(1.9)$ & $-4.3(2.0)$ & $-4.6(2.3)$ & $-1.0(0.5)$ & $18.0(7.4)$ \\
\hline & & \multicolumn{3}{|c|}{ Extension } & & \\
\hline & L1-L2 & L2-L3 & L3-L4 & L4-L5 & L5-S1 & L1-S1 Total \\
\hline Harvested & $2.8(1.2)$ & $2.0(0.9)$ & $2.3(0.8)$ & $2.6(1.2)$ & $3.7(1.6)$ & $13.5(4.5)$ \\
\hline Prodisc-L & $5.0(1.2)$ & $3.7(1.6)$ & $3.7(1.3)$ & 4.7 (1.9) & $4.8(2.2)$ & $22.0(6.4)$ \\
\hline Maverick & $4.5(1.7)$ & $3.5(1.6)$ & $3.9(1.5)$ & $3.8(1.9)$ & $7.1(3.6)$ & $22.8(9.1)$ \\
\hline Charite & $4.0(1.2)$ & $3.1(0.9)$ & $3.8(0.9)$ & $4.5(2.0)$ & $4.9(2.8)$ & $20.2(6.7)$ \\
\hline Fusion & $4.5(1.9)$ & $3.5(1.9)$ & $3.7(1.4)$ & $4.0(2.2)$ & $1.2(0.6)$ & $16.9(6.3)$ \\
\hline & & \multicolumn{3}{|c|}{ Left Lateral Bending } & & \\
\hline & L1-L2 & L2-L3 & L3-L4 & L4-L5 & L5-S1 & L1-S1 Total \\
\hline Harvested & $-4.0(1.1)$ & $-4.3(1.6)$ & $-5.1(1.7)$ & $-3.2(0.8)$ & $-2.4(0.8)$ & $19.0(4.6)$ \\
\hline Prodisc-L & $-4.6(1.1)$ & $-4.4(1.3)$ & $-5.8(2.3)$ & $-3.7(1.3)$ & $-2.2(1.2)$ & $20.7(4.6)$ \\
\hline Maverick & $-4.6(1.2)$ & $-4.5(1.9)$ & $-6.6(2.2)$ & $-4.2(1.2)$ & $-2.8(0.7)$ & $22.8(4.4)$ \\
\hline Charite & $-4.1(1.7)$ & $-5.1(2.1)$ & $-5.5(1.1)$ & $-3.6(1.1)$ & $-3.6(0.5)$ & $22.0(4.5)$ \\
\hline Fusion & $-4.6(1.4)$ & $-4.6(1.8)$ & $-5.3(1.9)$ & $-3.4(1.4)$ & $-0.7(0.4)$ & $18.5(5.1)$ \\
\hline & & \multicolumn{3}{|c|}{ Right Lateral Bending } & & \\
\hline & L1-L2 & L2-L3 & L3-L4 & L4-L5 & L5-S1 & L1-S1 Total \\
\hline Harvested & $4.1(1.1)$ & $3.7(1.5)$ & $5.2(1.2)$ & $3.4(1.3)$ & $2.2(0.8)$ & $18.5(3.0)$ \\
\hline Prodisc-L & $4.4(1.7)$ & $3.9(1.8)$ & $4.3(1.4)$ & $3.5(1.5)$ & $1.9(1.1)$ & $18.0(5.2)$ \\
\hline Maverick & $4.1(0.7)$ & $4.3(2.1)$ & $5.1(1.3)$ & $3.4(1.3)$ & $2.6(0.8)$ & $19.5(4.9)$ \\
\hline Charite & $4.3(1.1)$ & $4.7(1.5)$ & $5.6(0.7)$ & $4.2(1.5)$ & $3.7(0.6)$ & $22.5(1.8)$ \\
\hline Fusion & $4.6(1.3)$ & $4.2(2.4)$ & $5.2(1.7)$ & $3.4(1.6)$ & $0.7(0.3)$ & $18.0(4.9)$ \\
\hline & & \multicolumn{3}{|c|}{ Right Axial Rotation } & & \\
\hline & L1-L2 & L2-L3 & L3-L4 & L4-L5 & L5-S1 & L1-S1 Total \\
\hline Harvested & $1.0(0.7)$ & $1.2(0.7)$ & $1.7(0.9)$ & $2.0(1.2)$ & $1.8(1.1)$ & $7.7(2.1)$ \\
\hline Prodisc-L & $1.0(0.5)$ & $1.3(0.7)$ & $1.4(0.8)$ & $1.7(0.5)$ & $1.7(1.0)$ & $7.1(2.5)$ \\
\hline Maverick & $1.0(0.3)$ & $1.4(1.2)$ & $1.4(0.5)$ & $2.4(0.8)$ & $2.4(1.1)$ & $8.6(3.0)$ \\
\hline Charite & $1.7(0.6)$ & $1.7(1.2)$ & $2.1(0.6)$ & $2.1(0.9)$ & $2.5(1.4)$ & $10.1(2.3)$ \\
\hline Fusion & $0.9(0.6)$ & $1.7(1.2)$ & $2.2(1.2)$ & $2.1(1.3)$ & $0.5(0.4)$ & $7.4(3.1)$ \\
\hline & & \multicolumn{3}{|c|}{ Left Axial Rotation } & & \\
\hline & L1-L2 & L2-L3 & L3-L4 & L4-L5 & L5-S1 & L1-S1 Total \\
\hline Harvested & $-0.8(0.5)$ & $-1.2(0.8)$ & $-1.8(0.9)$ & $-1.9(0.9)$ & $-1.7(0.6)$ & $7.3(1.9)$ \\
\hline Prodisc-L & $-1.0(0.3)$ & $-1.0(0.4)$ & $-1.3(0.7)$ & $-1.8(0.8)$ & $-1.2(1.0)$ & $6.2(1.4)$ \\
\hline Maverick & $-1.0(0.4)$ & $-1.6(1.2)$ & $-1.6(0.9)$ & $-2.2(1.0)$ & $-2.0(0.8)$ & $8.4(3.1)$ \\
\hline Charite & $-1.6(0.5)$ & $-1.5(1.6)$ & $-2.9(0.7)$ & $-2.7(1.8)$ & $-3.2(1.3)$ & $11.8(4.1)$ \\
\hline Fusion & $-1.0(0.5)$ & $-1.5(1.2)$ & $-1.9(0.9)$ & $-1.8(1.3)$ & $-0.6(0.7)$ & $6.9(2.8)$ \\
\hline
\end{tabular}




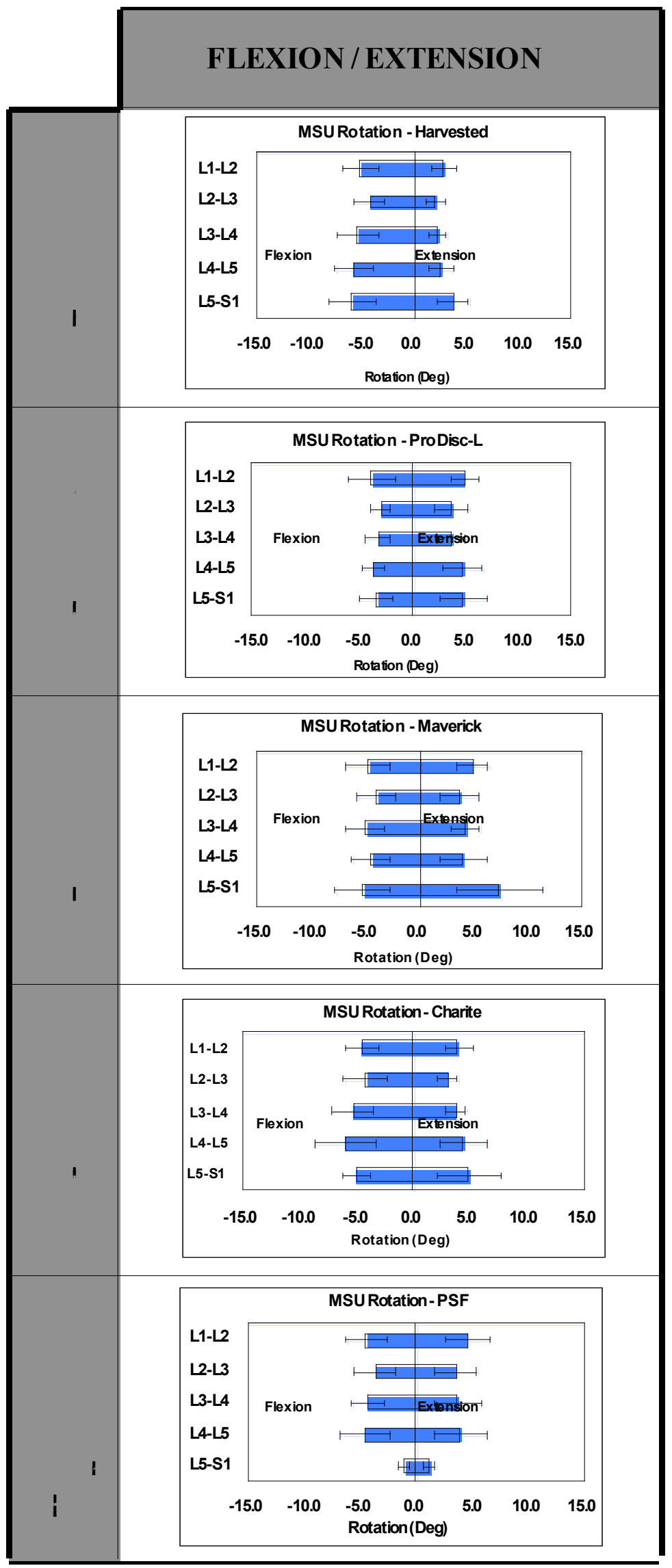

Fig. (6). Individual motion segment unit (MSU) rotations for each spine condition during flexion and extension. 


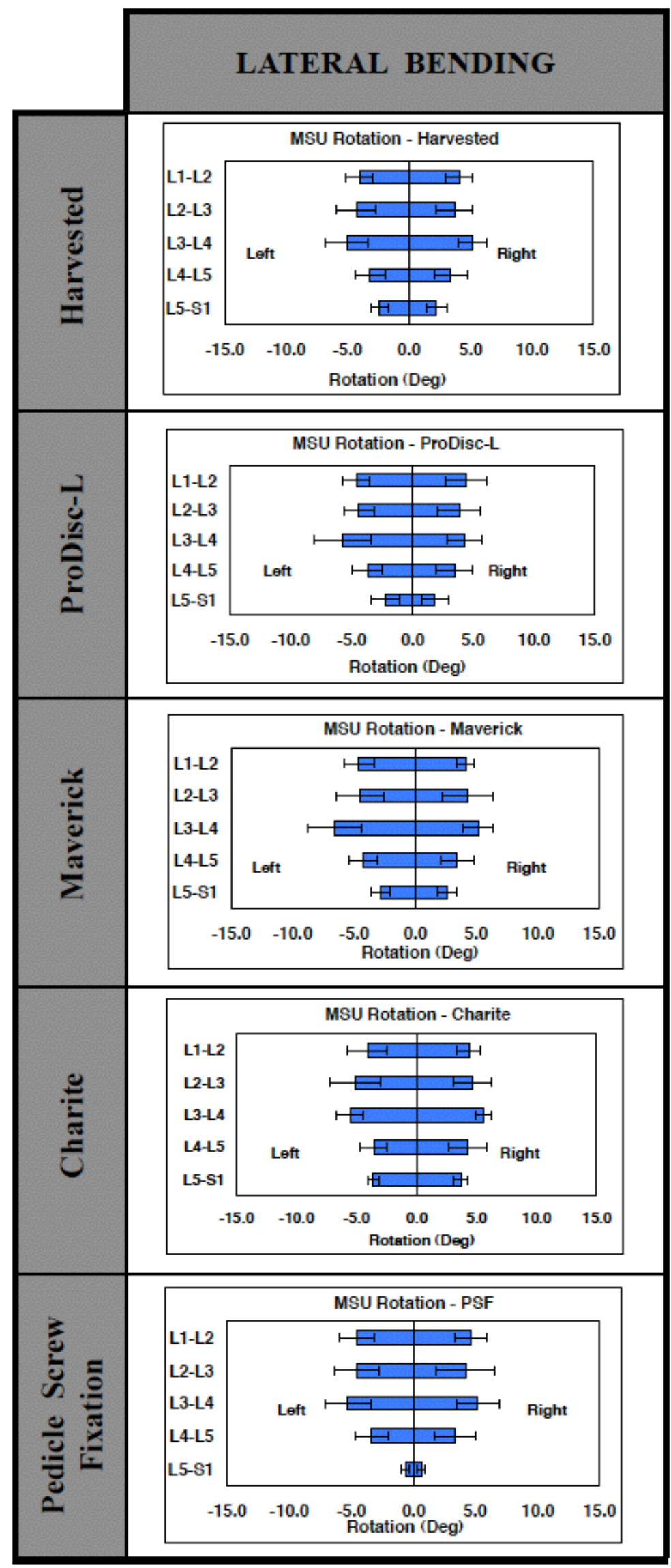

Fig. (7). Individual motion segment unit (MSU) rotations for each spine condition during lateral bending. 


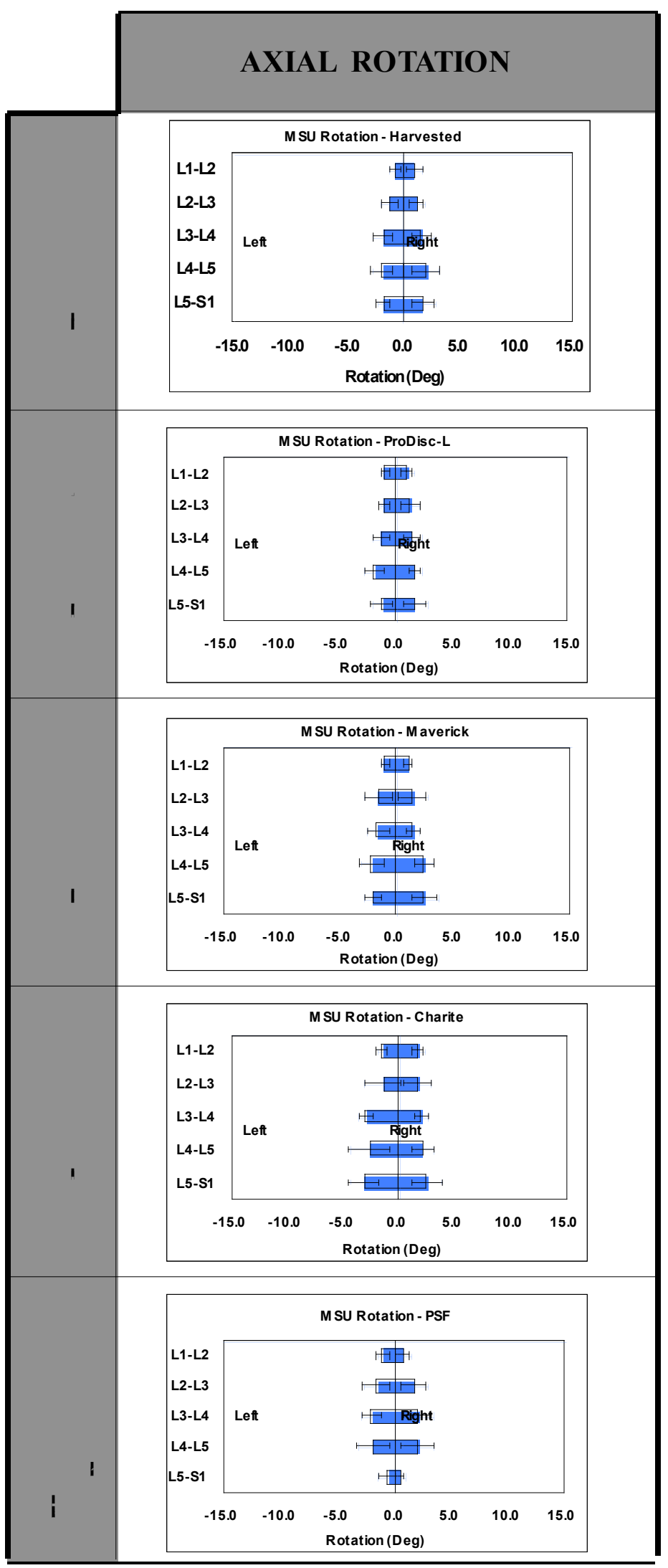

Fig. (8). Individual motion segment unit (MSU) rotations for each spine condition during axial rotation. 


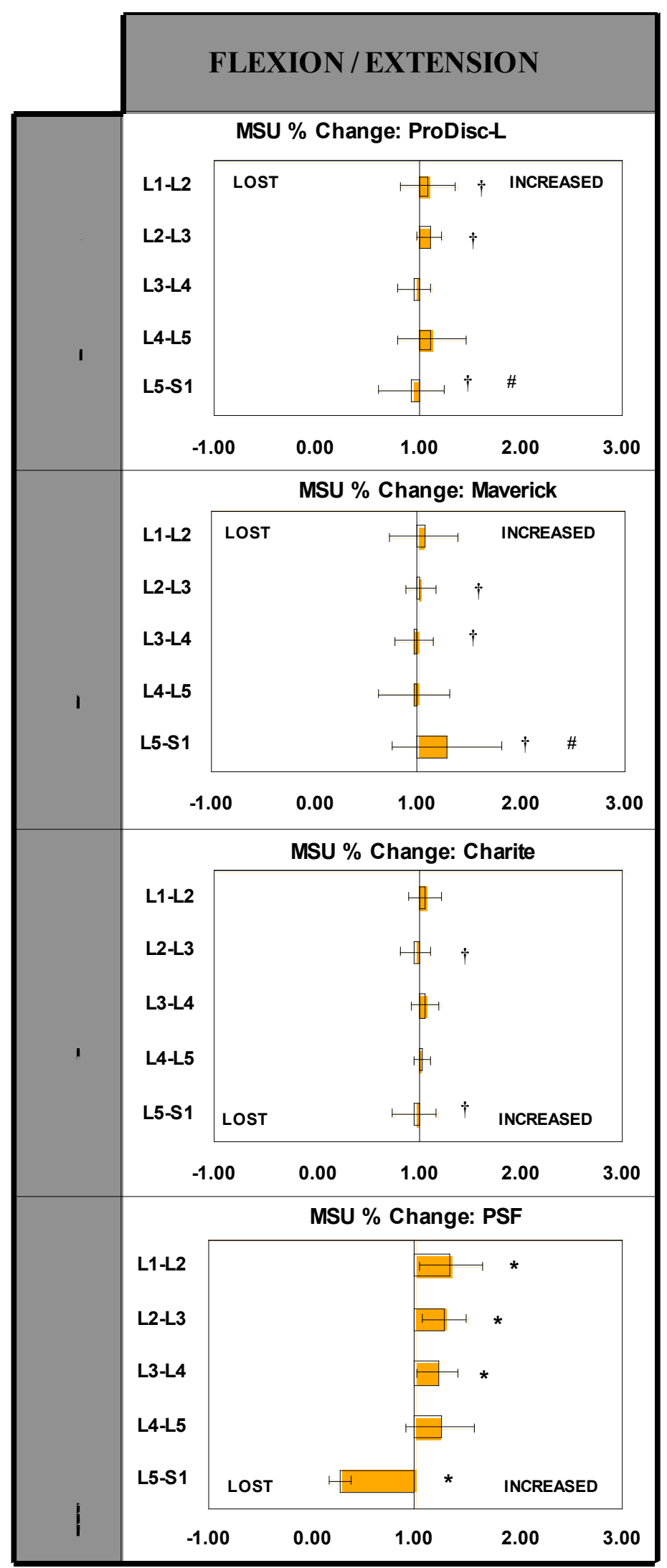

Fig. (9). Percent changes in MSU rotations for the altered spine conditions normalized to the harvested condition (* Signifies significant difference between the harvested condition, $\uparrow$ Signifies significant difference with respect to the fixated condition, \# Signifies significant difference between the ProDisc-L and Maverick disc implanted conditions). 


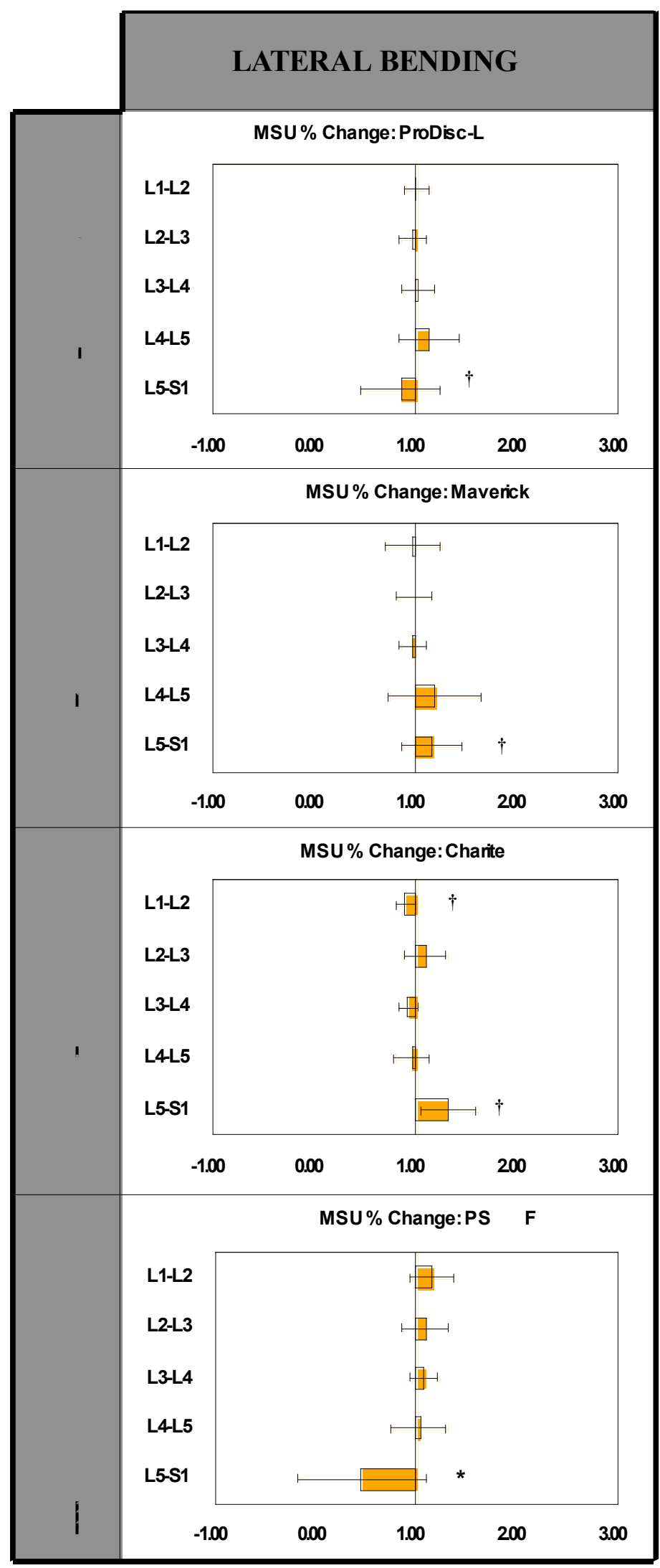

Fig. (10). Percent changes in MSU rotations for the altered spine conditions normalized to the harvested condition during lateral bending. (* Signifies significant difference between the harvested condition, $\uparrow$ Signifies significant difference with respect to the fixated condition, \# Signifies significant difference between the ProDisc-L and Maverick disc implanted conditions). 


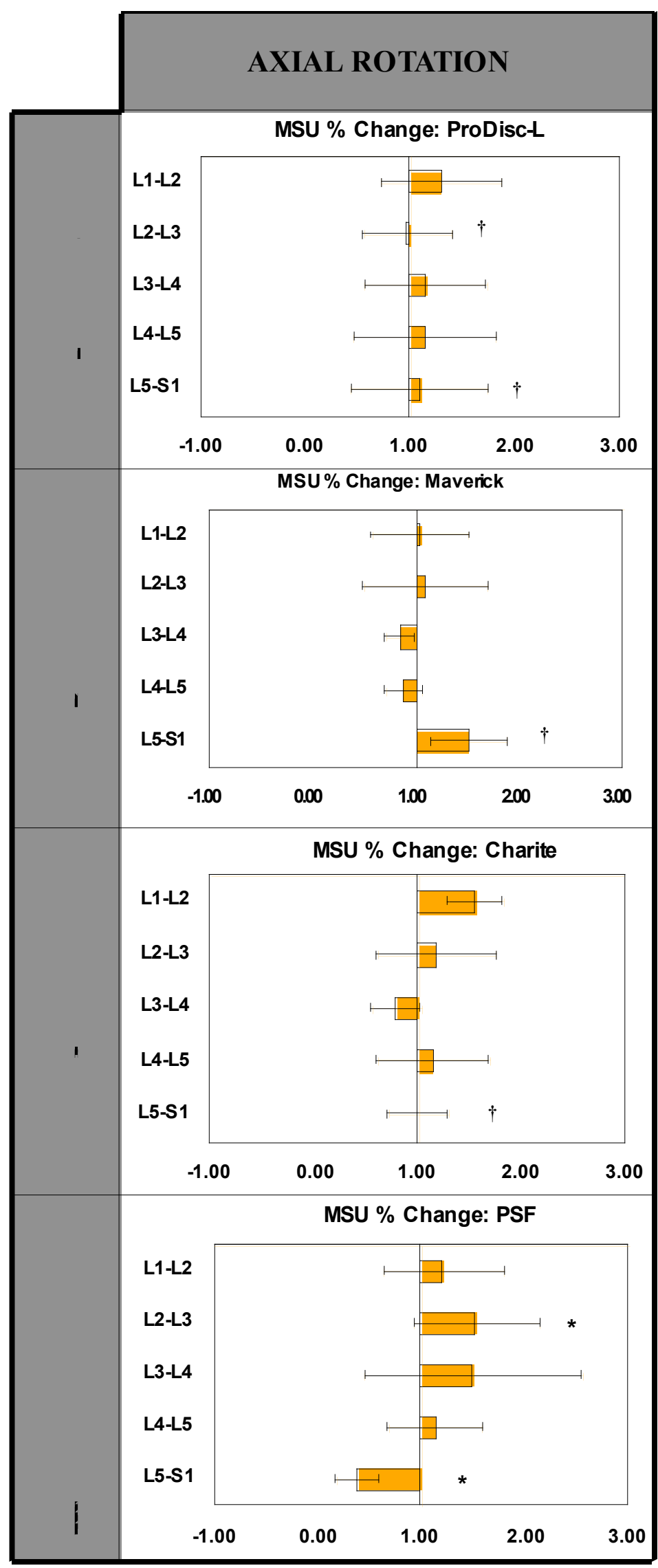

Fig. (11). Percent changes in MSU rotations for the altered spine conditions normalized to the harvested condition during axial rotation. (* Signifies significant difference between the harvested condition, $\dagger$ Signifies significant difference with respect to the fixated condition, \# Signifies significant difference between the ProDisc-L and Maverick disc implanted conditions). 
In the hybrid protocol [10] excessive movement beyond the harvested condition is less likely to be detected since specimens are never moved beyond the global harvested range of motion. Reported increases in segmental motion at the instrumented level may be the result of reduced stability due to the surgical procedure itself as opposed to implant design or function.

In the current study, the biomechanical stability and range of motion of the ProDisc-L, Maverick and Charité total disc prostheses and segmental pedicle fixation were compared directly in-vitro at a common end load limit. With respect to spinal flexibility significant changes occurred for the different spine motions, most notably during extension loading of the disc prostheses. These changes were attributed more to the nature of the surgical procedure itself; severing of the anterior longitudinal ligament and replacement of the disc with a mechanical device that cannot resist tension.

Posterior pedicle screw and rod instrumentation without disc implant removal simulated a salvage operation that caused a significant reduction in motion contribution at the treated level compared to the Harvested and all TDR conditions for all modes of testing. For this Fixated condition significant increases occurred across all of the uninstrumented adjacent MSU levels during flexion-extension and at L2-L3 during axial rotation. The increased motion response at these adjacent levels may contribute to the advancement of degenerative changes at these spinal levels.

All three TDR conditions maintained mobility at the treated level. None of the TDR spine conditions resulted in significantly increased or decreased spinal movement at all levels superior to the operated region (L1-L5).

Mean flexion-extension L5-S1 ROM for the Harvested, ProDisc-L, Charité, and Maverick conditions were 9.6, 8.1, 9.8, and 12.3 degrees, respectively. These data agree well with published clinical results from Ziegler et al. [32] reporting a mean flexion-extension ROM of 7.7 degrees in 286 patients at 24 months follow-up with ProDisc-L, and both Thierry [33] and Lemaire et al. [34] who reported flexion-extension ROM's of 10.1 and 10 degrees respectively after 10 -year follow-ups of the Charité total disc. In the current study the Charité and Maverick discs demonstrated mean L5-S1 ROM's that were all greater than the Harvested ROM, the Charite producing the greatest ROM in combined lateral bending and torsion. The mean ROM for the ProDisc-L was less than that for the Harvested condition for all modes of testing. Other clinical studies have pointed towards a similar observation. For the ProDisc-L implant, Huang et al. [35] reported a mean in-vivo flexionextension range of motion of 4 degrees at 8.7-years followup. In a 2-year follow-up, Leivseth et al. [36] reported that motion at the treated level with ProDisc-L was restored to $74 \%$ of the untreated ROM and to $45 \%$ of ROM for a 'normal' population data base. The authors pointed to soft tissue adaptation as well as factors not controlled in the study such as implant sizing, placement and surgical technique as possible reasons for the poor outcome. Siepe et al. [37] reported significantly reduced L5-S1 ROM from 8.1 degrees post operatively to 5.1 degrees following application of the ProDisc-L in 62 patients after 42 months follow-up. Lastly, Shim et al. [38] clinically compared the ProDisc-L and
Charité discs at 3-years follow-up. Facet degeneration and ROM at L4-L5 were not significantly different between the two implants however, ROM at L5-S1 was significantly greater for Charité (11.2 degrees) than ProDisc-L (5.6 degrees).

In the current study the ProDisc-L implant demonstrated only a $7 \%$ motion contribution reduction at the instrumented level in flexion-extension that was significantly different from that of the Maverick implanted condition, which demonstrated a $28 \%$ increase. Both devices represent a constrained ball and socket type of device with similar locations for the radii of curvature in the lower vertebral body, however the COR of the ProDisc-L is $5 \mathrm{~mm}$ anterior to that of the Maverick when placed in the spine. We have previously investigated the effects of changing the location of a fixed COR on segmental mechanics and ROM in the intact human lumbar MSU [39]. Six lumbar MSU's were tested under kinematic input by varying fixed COR's to common end load limits using a multi-axis robotic testing frame. This study demonstrated that resulting segmental ROM was greater for a more posterior COR (10 degrees) versus an anterior COR (6.1 degrees). However, a more posterior placed CoR significantly increased the shear load across the disc plane. This data points toward the anteroposterior location of the fixed COR in a ball and socket type implant as being a significant factor (in addition to other mechanical and surgical variables) in determining segmental ROM.

Lastly, adjacent segment degeneration (ASD) following spinal fusion and the influence of total disc arthroplasty remains a controversial issue. Recent clinical evaluations support significant degenerative changes following fusion that are age related however, the clinical significance may be more limited since cases of symptomatic ASD are less in number with only the more severe cases affecting clinical outcome [5-7]. In the current study increased motion compensation attributed to ASD effects were observed following fusion, however, the increased MSU contribution did not only occur at spinal levels immediately adjacent to the treated level, but also at other non-adjacent spinal levels. A previous investigation on simulated fusion and ASD effects in the cervical spine conducted within our laboratory by Schwab et al. [40] yielded a similar result that is also consistent with the observations of Hoogendorn et al. [41]. In their study fusion of the L3-L4 vertebrae in an in-vivo goat model produced no adjacent level effects but severe degeneration one level removed from the fusion site.

\section{Study Limitations}

The current testing protocol applied a compressive load and rotational bending moment to the spine without any external shear load. Additional tests are warranted to understand the influence of shear forces on the immediate fixation of TDR devices as well as the impact of shear loads on segmental motion patterns. The loading conditions were idealized with no modeling of muscle forces included. However, use of follower load concepts [30] that also apply coupled conditions of a bending moment and compressive load to simulate muscle activity bear a negative connotation when used to evaluate disc arthroplasty devices as they may 
inadvertently stabilize the device beyond daily living conditions, where minimal muscle involvement occurs (i.e., upright stance, sitting, laying down). The results of the current study are indicative of the acute stability of the different spinal devices tested. Variations in surgical procedure, including sagittal alignment and disc angle, were not documented nor controlled. The ProDisc-L and Maverick prostheses employ a single keel for initial fixation that may have been compromised during the removal of one disc and reinsertion of the other one. However, none of the discs showed signs of loosening and all discs remained stable throughout the duration of the study. Measures of importance

\section{CONCLUSION}

Issues pertaining to adjacent segment disease (ASD) with pedicle screw fixation surgery were supported by increased motion contributions at multiple sub-adjacent segments. However, disc arthroplasty eliminated any significant increase and may delay or prevent ASD. Compared to pedicle screw fixation, all three differently designed disc prostheses (ProDisc- L, Maverick, and Charité) remained stable and provided improved lumbar mobility. The only notable difference between the disc designs was the increased flexion-extension motion at the operative level of the Maverick disc compared to the ProDisc-L and may relate to A-P positioning of the device COR. The extent to which implant design affects long term survival and function remains unclear. Additional studies investigating coupled loading scenarios (flexion-extension or lateral bending with axial rotation) and/or measurement of the shear loads across the disc may help to further explain the influences of the different design features found in these mechanical disc prostheses.

\section{CONFLICT OF INTEREST}

The authors confirm that this article content has no conflicts of interest.

\section{ACKNOWLEDGEMENTS}

Research support from Synthes Spine, West Chester, PA. Use of the surgical facility at the Medical Education Research Institute, Memphis, TN.

\section{REFERENCES}

[1] Deyo RA, Mirza SK, Martin BI. Back pain prevalence and visit rates: estimates from U.S. national surveys, 2002. Spine 2006; 31(23): 2724-7.

[2] Fritzell P, Hagg O, Wessberg P, Nordwall A. Chronic low back pain and fusion: a comparison of three surgical techniques: a prospective multicenter randomized study from the Swedish lumbar spine study group. Spine 2002; 27: 1131-41.

[3] Harrop JS, Youssef JA, Maltenfort M, et al. Lumbar adjacent segment degeneration and disease after arthrodesis and total disc arthroplasty. Spine 2008; 33: 1701-7.

[4] Levin DA, Hale JJ, Bendo JA. Adjacent segment degeneration following spinal fusion for degenerative disc disease. Bull NYU Hosp Joint Dis 2007; 65: 29-36.

[5] Cheh G, Bridwell KH, Lenke LG, et al. Adjacent segment disease following lumbar/thoracolumbar fusion with pedicle screw instrumentation: A minimum 5-year follow-up. Spine 2007; 32: 2253-7.

[6] Schulte TL, Leistra F, Bullmann V, et al. Disc height reduction in adjacent segments and clinical outcome 10 years after lumbar 360 degrees fusion. Eur Spine J 2007; 16: 2152-8.

[7] Ekman P, Moller H, Shalabi A, Yu YX, Hedlund R. A prospective randomized study on the long-term effect of lumbar fusion on adjacent disc degeneration. Eur Spine J 2009; 18: 1175-86.

[8] Phillips FM, Garfin SR. Cervical disc replacement. Spine 2005; 30(17-Suppl): S27-33.

[9] Panjabi MM. Biomechanical evaluation of spinal fixation devices: I. A conceptual framework. Spine 1988; 13: 1129-34.

[10] Panjabi MM. Hybrid multidirectional test method to evaluate spinal adjacent-level effects. Clin Biomech 2007; 22: 257-65.

[11] DiAngelo DJ, Scifert JL, Kitchel S, Cornwall GB, McVay BJ. Bioabsorbable anterior lumbar plate fixation in conjunction with cage-assisted anterior interbody fusion. J Neurosurg 2002; $97(4$ Suppl): 447-55.

[12] Wido DM, Kelly BP, Morrow B, et al. Biomedical Comparison of Lumbar Disc Arthroplasty: ProDisc-L, Charite, and Marveric Disc Implant Systems, 25th Southern Biomedical Engineering Conference 2009, 15 - 17 May 2009, Miami, Florida, USA, IFMBE Proceedings 2009, vol. 24, pp. 223-6.

[13] Dvorak J, Panjabi MM, Chang DG, Theiler R, Grob D. Functional radiographic diagnosis of the lumbar spine: flexion/extension and lateral bending. Spine 1991; 16: 562-71.

[14] Pearcy MJ, Portek I, Shepherd J. Three-dimensional x-ray analysis of normal movement in the lumbar spine. Spine 1984; 9: 294-7.

[15] Froning EC, Frohman B. Motion of the lumbosacral spine after laminectomy and spine fusion: Correlation of motion with the result. J Bone Joint Surg Am 1968; 50: 897-918.

[16] White AA, Panjabi MM. Clinical Biomechanics of the Spine, $2^{\text {nd }}$ ed. J.B. Lippincott Co: Philadelphia 1990.

[17] Barnes D, Stemper BD, Yogananan N, Baisden JL, Pintar FA. Noermal coupling behavior between axial rotation and lateral bending in the lumbar spine -Biomed Sci Instrum 2009; 45: 131-6.

[18] Fujii R, Sakaura H,Mukai Y, et al. Kinematics of the lumbar spine in trunk rotation: in vivo three-dimensional analysis using magnetic resonance imaging. Eur Spine J 2007; 16(11): 1867-74.

[19] Shin JH, Wang S, Yao Q, Wood KB, Li G. Investigation of coupled bending of the lumbar spine during dynamic axial rotation of the body. Eur Spine J 2013; 22(12): 2671-7.

[20] Wilke H-J, Wenger K, Claes L. Testing criteria for spinal implants: recommendations for the standardization of in vitro stability testing of spinal implants. Eur Spine J 1998; 7: 148-54.

[21] Demetropoulos CK, Sengupta DK, Knaub MA, et al. Biomechanical evaluation of the kinematics of the cadaver lumbar spine following disc replacement with the ProDisc-L prosthesis. Spine (Phila Pa 1976) 2010; 35(1): 26-31.

[22] Dahl MC, Ellingson AM, Mehta HP, Huelman JH, Nuckley DJ. The biomechanics of a multilevel lumbar spine hybrid using nucleus replacement in conjunction with fusion. Spine J 2013; 13(2): 175-83.

[23] Huang RC, Girardi FP, Cammisa FP, Wright TM. The implications of constraint in lumbar total disc replacement. J Spinal Disord Tech 2003; 16: 412-7.

[24] Hitchon PW, Eichholz K, Barry C, et al. Biomechanical studies of an artificial disc implant in the human cadaveric spine. J Neurosurg Spine 2005; 2: 339-43.

[25] Cunningham BW, Gordon JD, Dmitriev AE, Hu N, McAfee PC. Biomechanical evaluation of total disc replacement arthroplasty; an in vitro human cadaveric model. Spine 2003; 28: S110-7.

[26] Goel VK, Grauer JN, Patel TC, et al. Effects of Charite artificial disc on the implanted and adjacent spinal segments using a hybrid testing protocol. Spine 2005; 30(24): 2755-64.

[27] O'Leary P, Nicolakis M, Lorenz MA, et al. Response of Charite total disc replacement under physiologic loads: prosthesis component motion patterns. Spine J 2005; 5: 590-9.

[28] Panjabi M, Malcolmson G, Teng E, Tominaga Y, Henderson G, Serhan H. Hybrid testing of lumbar Charite discs versus fusion. Spine 2007; 32: 959-66.

[29] Panjabi M, Henderson G, Abjornson C, Yue J. Multidirectional testing of one and two level ProDisc-L versus simulated fusions. Spine 2007; 32: 1311-9. 
[30] Patwardhan AG, Havey RM, Meade KP, Lee B, Dunlap B. A follower load increases the load-carrying capacity of the lumbar spine in compression. Spine 1999; 24: 1003-9.

[31] Cunningham BW, Hu N, Beatson HJ, Serhan H, Sefter JC, McAfee PC. Revision strategies for single- and two-level total disc arthroplasty procedures: A biomechanical perspective. Spine J 2009; 9(9): 735-43.

[32] Zigler J, Delamarter R, Spivak JM, et al. Results of the prospective, randomized, multicenter food and drug administration investigational device exemption study of the ProDisc-L total disc replacement versus circumferential fusion for the treatment of 1level degenerative disc disease. Spine 2007; 32: 1155-62.

[33] Thierry D. Long-term results of one-level lumbar arthroplasty, minimum 10-year follow-up of the Charite artificial disc in 106 patients. Spine 2007; 32: 661-6.

[34] Lemaire JP, Carrier H, Ali el-HS, Skalli W, Lavaste F. Clinical and radiological outcomes with the Charite artificial disc: a 10-year minimum follow-up. J Spinal Disord Tech 2005; 18: 353-9.

[35] Huang RC, Girardi FP, Cammisa FP, Tropiano P, Marnay T. Longterm flexion-extension range of motin of the Prodisc total disc replacement. J Spinal Disord Tech 2003; 16: 435-40.
[36] Leivseth G, Braaten S, Frobin W, Brinckmann P. Mobility of lumbar segments instrumented with a ProDisc II prosthesis, a twoyear follow-up study. Spine 2006; 31: 1726-33.

[37] Siepe CJ, Hitzl W, Meschede P, Sharma AK, Khattab MF, Mayer $\mathrm{MH}$. Interdependence between disc height, range of motion and clinical outcome in total lumbar disc replacement. Spine 2009; 34: 904-16.

[38] Shim CS, Lee SH, Shin HD, et al. Charite versus ProDisc, a comparative study of a minimum 3-year follow-up. Spine 2007; 32 : 1012-18.

[39] Zufelt NA, Sander EJ, Kelly BP, DiAngelo DJ. A Kinematics Based Testing Protocol For Studying Lumbar Disc Dynamics, Proceedings of the ASME 2008 Summer Bioengineering Conference (SBC 2008-191656), June 25-29, Marco Island, Florida 2008.

[40] Schwab JS, DiAngelo DJ, Foley KT. Motion compensation associated with single-level fusion: where does the lost motion go? Spine 2006; 31: 2439-48.

[41] Hoogendoorn RJ, Helder MN, Wuisman PI, Bank RA, Everts VE, Smit TH. Adjacent segment degeneration: observations in a goat spinal fusion study. Spine 2008; 33: 1337-43.

(C) DiAngelo et al.; Licensee Bentham Open .

This is an open access article licensed under the terms of the Creative Commons Attribution Non-Commercial License (http://creativecommons.org/licenses/by$\mathrm{nc} / 3.0 /$ ), which permits unrestricted, non-commercial use, distribution and reproduction in any medium, provided the work is properly cited. 